Article

\title{
Structure and Properties of 1,3-Phenylenediboronic Acid: Combined Experimental and Theoretical Investigations
}

\author{
Agnieszka Adamczyk-Woźniak ${ }^{1, *}$, Michał K. Cyrański ${ }^{2}$, Krzysztof Durka ${ }^{1}{ }^{\oplus}$, Jan T. Gozdalik ${ }^{1}$, \\ Paulina Klimentowska ${ }^{2}$, Rafał Rusiecki ${ }^{1,3}$, Andrzej Sporzyński ${ }^{1}$ and Dorota Zarzeczańska ${ }^{4}$ \\ 1 Faculty of Chemistry, Warsaw University of Technology, Noakowskiego 3, 00-664 Warsaw, Poland; \\ kdurka@gmail.com (K.D.); jgozdalik@ch.pw.edu.pl (J.T.G.); Rafal.Rusiecki@adamed.com (R.R.); \\ spor@ch.pw.edu.pl (A.S.) \\ 2 Faculty of Chemistry, University of Warsaw, Pasteura 1, 02-093 Warsaw, Poland; \\ mkc@chem.uw.edu.pl (M.K.S.); parog@chem.uw.edu.pl (P.K.) \\ 3 Adamed Pharma S.A., Pieńków, Adamkiewicza 6A, 05-152 Czosnów, Poland \\ 4 Faculty of Chemistry, University of Gdańsk, Wita Stwosza 63, 80-308 Gdańsk, Poland; \\ dorotazarzeczanska@gmail.com \\ * Correspondence: agnieszka@ch.pw.edu.pl; Tel.: +48-22-234-6147; Fax: +48-22-628-2741
}

Received: 16 January 2019; Accepted: 15 February 2019; Published: 19 February 2019

\begin{abstract}
The structure and properties of 1,3-phenylenediboronic acid are reported. Molecular and crystal structures were determined by single crystal as well as by powder X-ray diffraction methods. Acidity constant, thermal behavior, and NMR characterization of the title compound were also investigated. In addition to the experimental data, calculations of rotational barrier and intermolecular interaction energies were performed. The compound reveals a two-step acid-base equilibrium with different $\mathrm{p} K_{\mathrm{a}}$ values. TGA and DSC measurements show a typical dehydration reaction with formation of boroxine. In crystals, hydrogen-bonded dimers with syn-anti conformation of hydroxyl groups form large numbers of ribbon motifs. The 2D potential energy surface scan of rotation of two boronic groups with respect to phenyl ring reveals that the rotation barrier is close to $37 \mathrm{~kJ} \cdot \mathrm{mol}^{-1}$, which is higher than the double value for the rotation of the boronic group in phenylboronic acid. This effect was ascribed to intermolecular interaction with $\mathrm{C}-\mathrm{H}$ hydrogen atom located between boronic groups. Furthermore, the molecules in the crystal lattice adopt a less stable molecular conformation most likely resulting from intermolecular forces. These were further investigated by periodic DFT calculations supported by an estimation of dimer interaction energy, and also by topological analysis of electron density in the framework of AIM theory.
\end{abstract}

Keywords: boronic acid; 1,3-phenylenediboronic acid; crystal structure; DSC; TGA; acidity constant; rotation barrier; DFT; AIM

\section{Introduction}

Increasing interest in the chemistry of boronic acids and derivatives is connected with their broad applications in organic synthesis, catalysis, supramolecular chemistry, and material engineering, as well as in biology and medicine [1-4]. Boronic acids, due to the presence of two hydroxyls in a flexible $\mathrm{B}(\mathrm{OH})_{2}$ group, can form various covalent as well hydrogen-bonded supramolecular assemblies. Dynamic covalent reactivity is the basis of application of boronic acids in the formation of covalent organic frameworks (COF) [5-8].

Diboronic acids are part of an especially important group due to their possibility of diverse spatial arrangement and the resulting use in the field of crystal engineering. The properties and 
applications of this class of compounds were recently reviewed [9]. There are numerous papers on the structures of diboronic acids. Confined only to diboronic acids in which both $\mathrm{B}(\mathrm{OH})_{2}$ groups are placed in the same benzene ring, many examples of structures are found in the literature. For para-phenylenediboronic acid, long chains with primary hydrogen-bonded bridges and secondary lateral hydrogen bonds between the chains are formed [10,11]. Water and other solvent molecules can participate in lateral hydrogen bonds in the crystal lattice [11,12]. Ortho-Phenylenediboronic acid can form several polymorphic forms [13]. Fluoro-substituted ortho-phenylenediboronic acids form several uncommon crystal structures $[14,15]$.

Compared with several publications on the above-mentioned isomers, much less attention has been devoted to meta-phenylenediboronic acid. The crystal structure of 2-methoxy-1,3-phenylenediboronic acid was determined by Dabrowski et al. [16], whereas the structure of 4-bromo-1,3-phenylenediboronic acid was reported by Luliński et al. [17]. The structure of a co-crystal of 1,3-phenylenediboronic acid with 4,4'-bipyridine was also described [18]. However, neither the structure nor the spectroscopic or physicochemical data for the basic unsubstituted meta isomer have been described in the literature so far. The aim of the present paper is to characterize 1,3-phenylenediboronic acid both in solid state and in solutions.

\section{Materials and Methods}

1,3-Phenylenediboronic acid was purchased from Manchester Organics at 98\% purity and it was used without further purification.

\section{1. $p K_{a}$ Determination}

Potentiometric titrations were performed with a microtitration automatic Cerko-Lab system equipped with a Schott Blue line $\mathrm{N} 16 \mathrm{pH}$ electrode and a $0.5 \mathrm{~mL}$ Hamilton syringe. The $\mathrm{pH}$ glass-electrode was calibrated with four buffer solutions. The resolution of the voltage measurements was $<0.1 \mathrm{mV}$. The compound was dissolved in an aqueous solution with a constant ionic strength $(0.1 \mathrm{M} \mathrm{KCl})$. The reagent concentrations were: boronic acid: $2.7 \times 10^{-3} \mathrm{M}, \mathrm{NaOH}$ solution: $0.0491 \mathrm{M}$. Potential was recorded every $30 \mathrm{~s}$.

Spectrophotometric titrations were performed on a Perkin Elmer UV-Vis spectrophotometer Lambda 650, using quartz cuvettes of a 1-cm light pathlength. Spectrophotometric titrations were performed under conditions analogous to those used for the potentiometric measurements. Spectral changes presented as $A=f(\lambda)$ take into account a correction to the dilution of the analyte during the measurement. All measurements were performed at $298 \mathrm{~K}$.

The dissociation constant values obtained with the potentiometric method were calculated using a STOICHIO version CV EQUID computer program which uses the non-linear least-squares Gauss-Newton-Marquardt method for fitting procedure [19-21].

The values obtained with spectrophotometric method were calculated with the Henderson-Hasselbalch equation implemented into the Origin Lab software. It is based on the change in absorption intensity as a function of $\mathrm{pH}$ of the solution [22].

\subsection{NMR Measurements}

${ }^{1} \mathrm{H}$ NMR and ${ }^{1} \mathrm{H}_{-}{ }^{13} \mathrm{C}$ HSQC experiments were done on Bruker Avance $500 \mathrm{MHz} .{ }^{11} \mathrm{~B}$ NMR and ${ }^{13} \mathrm{C}$ NMR were recorded on Bruker Avance $300 \mathrm{MHz}$. The residual solvent signals (DMSO) were used as internal references for ${ }^{1} \mathrm{H}$ and ${ }^{13} \mathrm{C}$ NMR shifts. $\mathrm{BF}_{3} \cdot \mathrm{OEt}_{2}$ in $\mathrm{CDCl}_{3}$ was used as external reference for ${ }^{11} \mathrm{~B}$ NMR spectrum.

\subsection{Single Crystal X-ray Diffraction}

Crystals of commercial 1,3-phenylenediboronic acid suitable for single crystal X-ray experiments were obtained by recrystallization from water. Crystal size was $0.2 \times 0.2 \times 0.3 \mathrm{~mm}$. The X-ray measurement was performed at 100(2) K on a KUMA CCD k-axis diffractometer (Rigaku, Wrocław, 
Poland) with graphite-monochromated Mo K $\alpha$ radiation (0.71073 $\AA$ ). The crystal was positioned $62.25 \mathrm{~mm}$ from the KM4CCD camera; 748 frames were measured at $0.8^{\circ}$ intervals on a counting time of $45 \mathrm{~s}$. Data collection, cell refinement and data reduction were carried out with the KUMA Diffraction programs: CrysAlis CCD and CrysAlis RED [23]. The data were corrected for Lorentz and polarization effects, but no absorption correction was applied. The structure was solved by direct methods [24] and refined by using SHELXL [25]. The refinement was based on $\mathrm{F}^{2}$ for all reflections except for those with very negative $\mathrm{F}^{2}$. The weighted $\mathrm{R}$ factor, $\mathrm{wR}$ and all goodness-of-fit $\mathrm{S}$ values were based on $\mathrm{F}^{2}$. The non-hydrogen atoms were refined anisotropically. The hydrogen atoms were located from a difference map and were refined isotropically. The atomic scattering factors were taken from the International Tables [26]. Crystallographic data for the structure have been deposited in the Cambridge Crystallographic Data Centre as supplementary publication No. 1874946. Copies of the data can be obtained on application to CCDC, 12 Union Road, Cambridge CB2 1EZ, UK (email: deposit@ccdc.cam.ac.uk). $\mathrm{C}_{6} \mathrm{H}_{8} \mathrm{~B}_{2} \mathrm{O}_{4}, \mathrm{M}=165.74$, monoclinic $C 2 / \mathrm{c}, \mathrm{a}=6.994(1) \AA, \mathrm{b}=7.124(1) \AA$, $\mathrm{c}=15.025(3) \AA, \beta=97.70(3)^{\circ}, \mathrm{V}=741.87(3) \AA^{3}, \mathrm{Z}=4, \mathrm{D}_{\mathrm{x}}=1.484 \mathrm{mg} / \mathrm{m}^{3}, \mu=0.117 \mathrm{~mm}^{-1}, \mathrm{~F}(000)=$ 344.0, $2 \Theta$ range for data collection $2.74-25.00^{\circ},-8<=\mathrm{h}<=8,-8<=\mathrm{k}<=7,-17<=1<=17$, Reflections collected/unique 2643/652 [R(int) $=0.0514]$, Goodness-of-fit on $\mathrm{F}^{2}=1.102$, Final R indexes $(I>=2 \sigma(I))$ were $R_{1}=0.0405, w R^{2}=0.1005$, Final $R$ indexes (all data) were $R_{1}=0.0449, w R^{2}=0.1039$, Largest diff. peak/hole were 0.313 and -0.252 e $\AA^{-3}$.

\subsection{X-ray Powder Diffraction (XRPD)}

X-ray powder diffraction patterns of solid phase were recorded with a Rigaku MiniFlex X-ray diffractometer (Danvers, MA, USA) using Cu K $\alpha$ radiation $(\lambda=1.54 \AA$ ), a tube voltage of $30 \mathrm{kV}$, and a tube current of $15 \mathrm{~mA}$. The intensities were measured at $2 \theta$ values from $2^{\circ}$ to $40^{\circ}$ at a continuous scan rate of $1^{\circ} / \mathrm{min}$.

\subsection{Thermal Analysis}

Thermal analysis was performed by means of the TG $209 \mathrm{~F} 1$ Nevio with a scan range of $25-300{ }^{\circ} \mathrm{C}$, scan rate of $10^{\circ} \mathrm{C} / \mathrm{min}$, and nitrogen purge of ca. $20 \mathrm{psi}$.

\subsection{Differential Scanning Calorimetry (DSC)}

Differential Scanning Calorimetry was performed on a Mettler Toledo DSC 1 with a scan range of 30-300 ${ }^{\circ} \mathrm{C}$, scan rate of $10{ }^{\circ} \mathrm{C} / \mathrm{min}$ or $25^{\circ} \mathrm{C} / \mathrm{min}$, and nitrogen flow $30 \mathrm{~mL} / \mathrm{min}$.

\subsection{Theoretical Calculations}

\subsubsection{CRYSTAL09 Calculations}

To provide more reliable geometries for further computational investigations, atomic coordinates were subjected to constrained optimization in the CRYSTAL09 program $[27,28]$. The starting geometry was taken directly from the X-ray structure. All X-H bonds were elongated to standard neutron distances prior to optimization [29]. In the first step, the positions of the atoms were optimized, wherein unit-cell parameters were constrained. Then, all parameters were subjected to the optimization. The obtained atomic positions (except hydrogen atoms) and unit-cell parameters were very similar to the experimental ones. The atomic coordinates obtained after periodic optimizations were used for further computational investigations in Gaussian09 and AIM.

All energy computations within the CRYSTAL09 program package were performed at the DFT(B3LYP) level of theory with POB triple-zeta valence + polarization basis set (TZVP) [30]. Both Grimme dispersion correction and correction for the basis set superposition error were applied [31,32]. Ghost atoms were selected up to a 15- $\AA$ distance from the studied molecule in a crystal lattice, and were used for the basis set superposition error estimation. The evaluation of Coulomb and exchange series was controlled by five thresholds, set arbitrary to values of $10^{-7}, 10^{-7}$, 
$10^{-7}, 10^{-7}, 10^{-25}$. The condition for the SCF convergence was set to $10^{-7}$ on the energy difference between two subsequent cycles. The shrinking factor was equal to 4, which refers to 30-36 k-points (depending on space group symmetry) in the irreducible Brillouin zone in the case of the studied system and assured the full convergence of the total energy. The cohesive energy $\left(E_{\text {coh }}\right)$ was calculated as described below:

$$
E_{\text {coh }}=\frac{1}{Z} E_{\text {bulk }}-E_{\text {mol }}
$$

where $E_{\text {bulk }}$ is the total energy of a system (calculated per unit cell) and $E_{\text {mol }}$ is the energy of a molecule extracted from the bulk. $Z$ stands for the number of molecules in the unit cell.

\subsubsection{Gaussian09 Calculations}

To calculate the dimer interaction energies, single-point calculations on M06-2X/6-311+ $\mathrm{G}^{* *}$ [33-35] level of theory were performed. The initial geometries were extracted from the CRYSTAL09 optimized structures. The obtained values were corrected for the basis-set superposition error using the counterpoise procedure. Based on optimized molecular geometry at the M06-2X/6-311+G* level of theory [34] a rotation barrier was calculated. Both boronic groups were rotated by 10 degrees in respect to the phenyl ring, while other parameters were fully optimized. The rotation barrier for phenylboronic acid was also calculated at the same level of theory, for comparison.

\subsubsection{Topological Analysis of Electron Density}

Theoretical charge density studies based on the quantum theory of atoms in molecules (QTAIM) [36,37] were performed using AIM2000 [38]. For this purpose, ab initio calculations for selected dimers were performed at the M06-2X/6-311+G $\mathrm{G}^{* *}$ level of theory using Gaussian 09.

\section{Results}

\subsection{Acidity Constants}

The acid-base equilibria of the title compound are described by a two-stage equation due to the presence of two boronic groups (Scheme 1).<smiles>OB(O)c1cccc(B(O)O)c1</smiles>

B<smiles></smiles>

$\mathbf{B}^{-}$

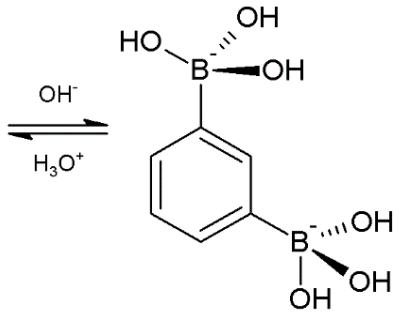

$B^{2-}$

Scheme 1. The acid-base equilibria of 1,3-phenylenediboronic acid.

The acid-base equilibrium constants $K_{\mathrm{a} 1}$ and $K_{\mathrm{a} 2}$ are described by the following equations:

$$
\begin{aligned}
& \mathrm{B}+2 \mathrm{H}_{2} \mathrm{O} \rightleftarrows B^{-}+\mathrm{H}_{3} \mathrm{O}^{+} \quad K_{a 1}=\frac{\left[B^{-}\right]\left[\mathrm{H}_{3} \mathrm{O}^{+}\right]}{[B]} \\
& B^{-}+2 \mathrm{H}_{2} \mathrm{O} \rightleftarrows B^{2-}+\mathrm{H}_{3} \mathrm{O}^{+} \quad K_{a 2}=\frac{\left[B^{2-}\right]\left[\mathrm{H}_{3} \mathrm{O}^{+}\right]}{\left[B^{-}\right]}
\end{aligned}
$$

The changes in the concentration of individual forms as a function of $\mathrm{pH}$ during potentiometric titrations are shown in Figure 1. 


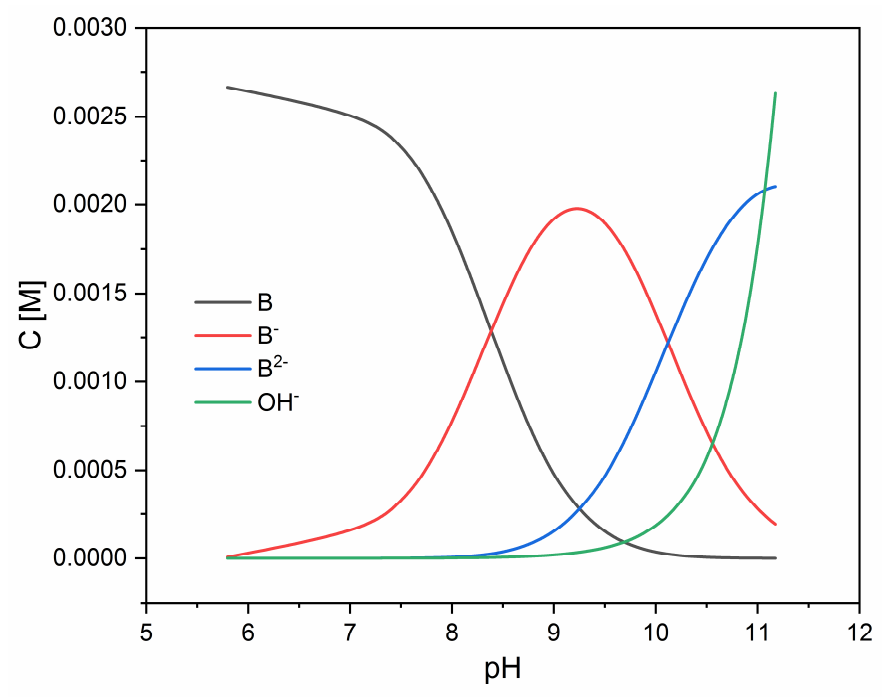

Figure 1. Species distribution diagram for the potentiometric titration.

Acidity constant $\left(\mathrm{p} K_{\mathrm{a}}\right)$ values were determined both by spectrophotometric and potentiometric method as described in [39]. Titration curves as well as analysis and fitting of the experimental data are presented in Supplementary Materials (Figures S1-S3). The $\mathrm{p} K_{\mathrm{a}}$ values are collected in Table 1.

Table 1. $\mathrm{p} K_{\mathrm{a}}$ values of $m$-phenylenediboronic acid.

\begin{tabular}{ccc}
\hline Method & Potentiometric & Spectrophotometric \\
\hline $\mathrm{p} K_{a 1}$ & $8.26 \pm 0.07$ & $8.31 \pm 0.01$ \\
$\mathrm{p} K_{a 2}$ & $9.97 \pm 0.09$ & $10.11 \pm 0.01$ \\
\hline
\end{tabular}

The $\mathrm{p} K_{\mathrm{a}}$ values determined by both methods show good agreement with each other. The $\mathrm{pH}-$ spectrophotometric titration curves demonstrate the existence of two equilibria, which correspond to two stages of dissociation. This is confirmed by the course of the absorbance vs $\mathrm{pH}$ curve (Figure S1). Also, the changes in the UV-Vis spectra during titration show that, in the first stage of the reaction, the absorption increases in almost the entire wavelength range and then the maximum at $274 \mathrm{~nm}$ decreases and shifts hipsochromically (Figure S2). On the curve of potentiometric titration, due to the small $\mathrm{p} K_{\mathrm{a}}$ value difference $\left(\Delta \mathrm{p} K_{\mathrm{a}}=1.8\right)$, there are no inflexions to confirm the reaction model (Figure S3). However, an almost perfect match of the calculated and measured parameters unambiguously confirmed the two-stage dissociation model of this boronic acid shown in Scheme 1.

\subsection{NMR Spectra}

${ }^{1} \mathrm{H},{ }^{13} \mathrm{C}$ and ${ }^{11} \mathrm{~B}$ NMR data for the title compounds are collected in Table 2. Due to its very low solubility in acetone, chloroform and toluene, the spectra were recorded in DMSO- $\mathrm{d}_{6}$. The assignment of the signals in ${ }^{13} \mathrm{C}$ NMR spectrum was done using ${ }^{1} \mathrm{H}_{-}{ }^{13} \mathrm{C}$ HSQC experiment (Figure 2). The one-dimensional spectra are shown in Supporting Materials (Figure S4). 
Table 2. Chemical shifts (ppm) and coupling constants $(J)$ for 1,3-phenylenediboronic acid in DMSO- $d_{6}$ atom numbering scheme shown at Figure 3.

\begin{tabular}{|c|c|c|c|c|}
\hline \multirow[b]{2}{*}{$\begin{array}{l}{ }^{1} \mathrm{H} \text { NMR } \\
(500 \mathrm{MHz})\end{array}$} & $\mathrm{OH}$ & $\mathrm{H} 2$ & H4, H6 & H5 \\
\hline & $\begin{array}{c}7.94 \\
\text { (broad) }\end{array}$ & $8.21(\mathrm{~s})$ & $\begin{array}{c}7.81(\mathrm{dd}) \\
{ }^{1} J=7.39 \mathrm{~Hz} \\
{ }^{4} J=1.35 \mathrm{~Hz}\end{array}$ & $\begin{array}{c}7.29(\mathrm{t}) \\
{ }^{1} J=7.39 \mathrm{~Hz}\end{array}$ \\
\hline \multirow{2}{*}{$\begin{array}{l}{ }^{13} \mathrm{C} \text { NMR } \\
(75 \mathrm{MHz})\end{array}$} & $\mathrm{C} 1, \mathrm{C} 3$ & $\mathrm{C} 2$ & $\mathrm{C} 4, \mathrm{C} 6$ & C5 \\
\hline & $\begin{array}{c}132.8 \\
\text { (broad) }\end{array}$ & 140.3 & 135.8 & 126.4 \\
\hline $\begin{array}{l}{ }^{11} \mathrm{~B} \mathrm{NMR} \\
(96 \mathrm{MHz})\end{array}$ & \multicolumn{4}{|c|}{30} \\
\hline
\end{tabular}

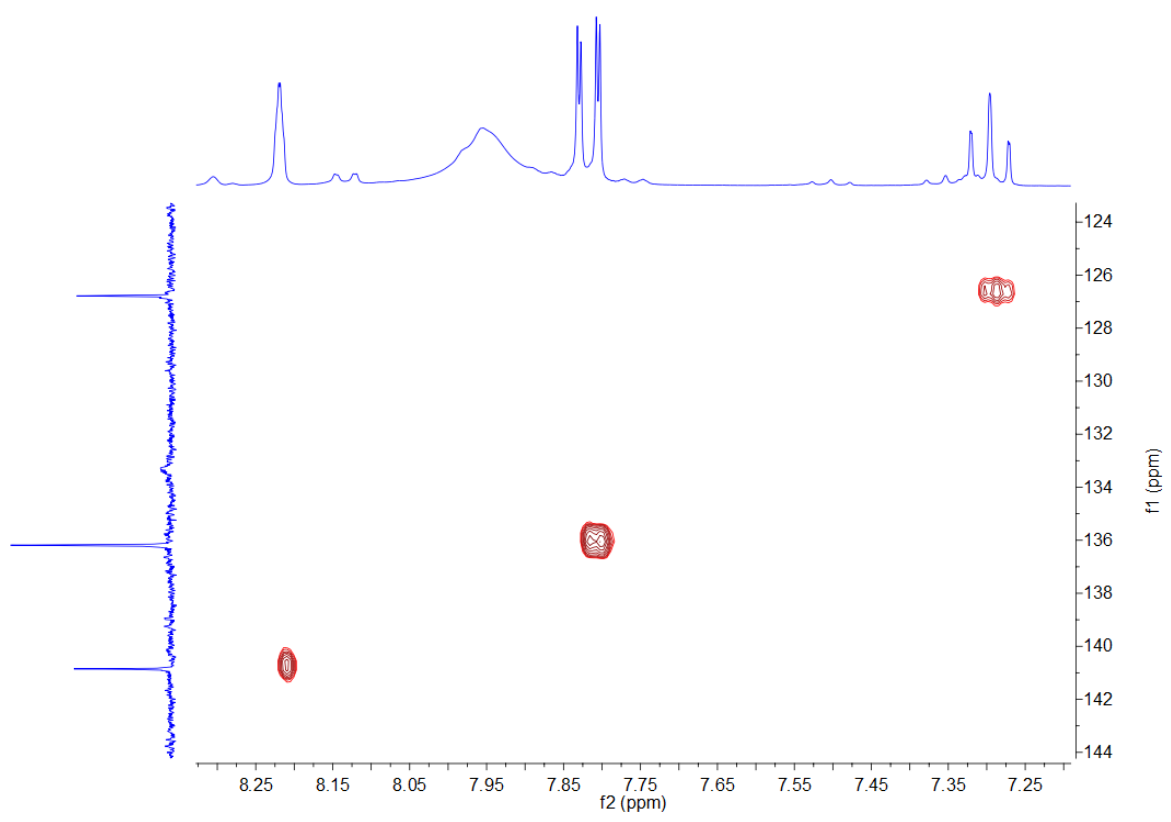

Figure 2. ${ }^{1} \mathrm{H}-{ }^{13} \mathrm{C}$ HSQC spectrum of the title compound.<smiles>OB(O)c1cccc(B(O)O)c1</smiles>

Figure 3. Atom numbering scheme for 1,3-phenylenediboronic acid.

\subsection{Thermal Behavior}

The thermal stability of the studied system was investigated under an $\mathrm{N}_{2}$ atmosphere by DSC as well as thermal analysis techniques. The amorphous sample purchased from Manchester (Figure 4) as well as the sample crystallized from water (Figure 5) were investigated. The DSC curves of both samples do not show any distinct changes corresponding to phase transition, solvent loss, dehydration or molecular rearrangement processes up to about $150{ }^{\circ} \mathrm{C}$. The dehydration temperature is higher than observed for monoboronic acids [40]. This fact can be connected with the different crystal structure of the diboronic compound, compared with the monoboronic ones. Several thermal effects are observed over a range of about $160-200{ }^{\circ} \mathrm{C}$ by DSC (Figures 4 and 5). Those effects are accompanied by a major mass loss (up to $21 \%$ ) observed for both investigated samples. The thermal analysis and DSC 
measurements were carried out up to $300{ }^{\circ} \mathrm{C}$ and neither additional thermal effects nor sample weigh loss were observed at temperatures higher than $250^{\circ} \mathrm{C}$.

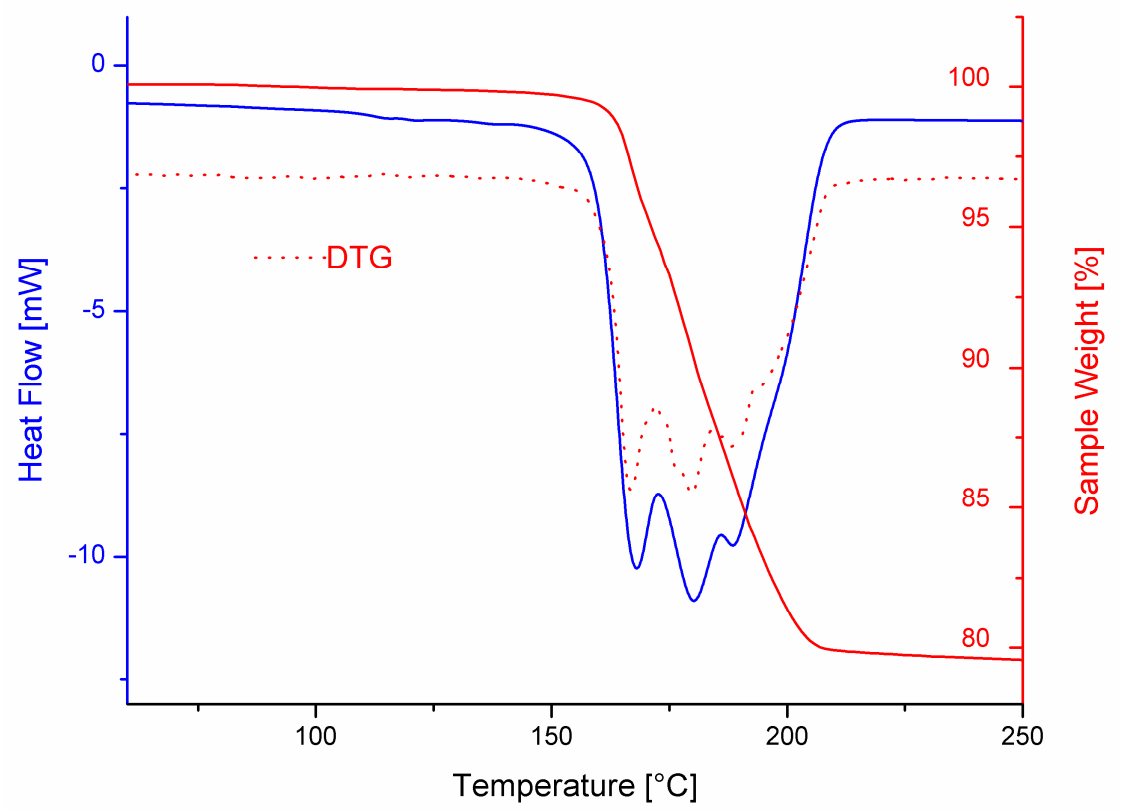

Figure 4. The DSC (blue), thermal (red), and differential thermal (red dotted) curves for the amorphous sample.

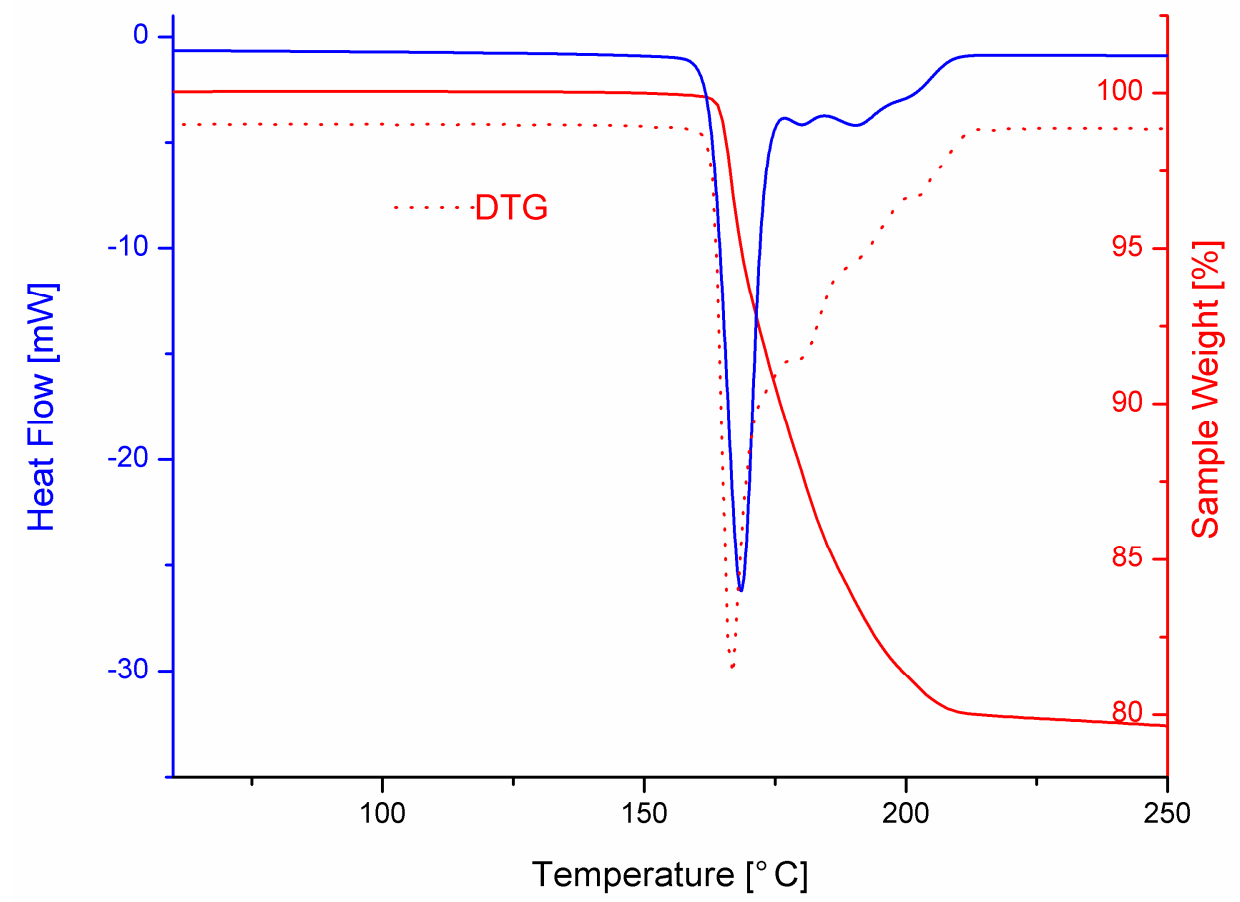

Figure 5. The DSC (blue), thermal (red), and differential thermal (red dotted) curves for the crystalline sample.

Similar shapes of the DSC and differential thermal curves as well as the total amount of sample weight loss confirm that all the observed thermal effects fall in with dehydration and water evaporation processes. The observed weight loss corresponds to the release of two molecules of water, which resembles typical behavior of arylboronic acids, that dehydrate to corresponding boroxines with the formation of a six-membered $\mathrm{B}_{3} \mathrm{O}_{3}$ ring (Scheme 2) [40]. The dehydration of a difunctional boronic 
system would presumably lead to the formation of a polymeric network. As shown by Yaghi et al., the controlled dehydration of 1,4-phenylenediboronic acid leads to the formation of porous crystalline COF-1 material [8]. However, in the case of 1,3-phenylenediboronic acid, the formation of amorphous polymer can be rather expected due to a different symmetry of the system.

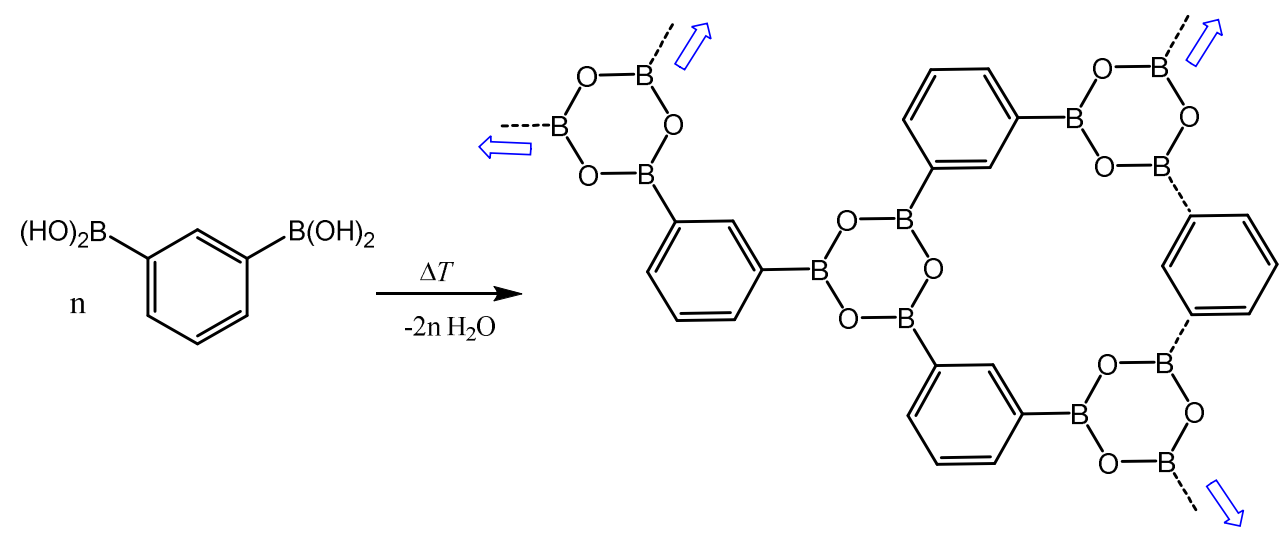

Scheme 2. Thermal dehydration of 1,3-phenylenediboronic acid leading to the 2D polymeric structure. Blue arrows show the polymer propagation.

\subsection{Molecular and Crystal Structure}

1,3-Phenylenediboronic acid crystallizes in a monoclinic system and C2/c symmetry space group, with half of molecule as the asymmetric part of the unit cell. The investigated molecule lies on a twofold axis. In the result, both boronic groups have the same geometry. In the structure of 1,3-phenylenediboronic acid molecules form dimeric units, the most common motif is observed in the structures of phenylboronic acids. In case of 1,3-phenylenediboronic acid, these dimeric units are centrosymmetric. The boronic groups show syn-anti conformation of hydroxyl groups. The group is not coplanar with the phenyl ring fragment. The twist between the boronic group plane and the phenyl ring plane equals $26.2(2)^{\circ}$. This can be easily affordable since the rotation barrier of a boronic group $\left(17.5 \mathrm{~kJ} \cdot \mathrm{mol}^{-1}\right)$ is relatively small [41] and, hence, the crystal field may easily distort the groups from planarity. This point was analyzed more in detail (see Theoretical Calculations section of the paper). Dimers interact in the crystal lattice with other units by hydrogen bonds. The formation of two intermolecular hydrogen bonds by each boronic unit generates a large number of ribbon motifs, typical for type II of Bettinger's classification [42] (Figure 6a). Intermolecular hydrogen bonds between dimers are slightly weaker than in those of type I, and slightly stronger than hydrogen bonds between units. Values of hydrogen bond parameters are shown in Table 3. Other selected geometrical parameters are collected in Supplementary Materials (Table S1).

Table 3. Hydrogen bond geometry $\left(\AA{ }^{\circ}{ }^{\circ}\right)$.

\begin{tabular}{cccccc}
\hline Donor-H & $\mathbf{d}(\mathbf{D}-\mathbf{H})$ & $\mathbf{d}(\mathbf{H} . . . \mathbf{A})$ & $<$ DHA & $\mathbf{d}(\mathbf{D} \ldots \mathbf{A})$ & Acceptor, Symmetry Code \\
\hline $\mathrm{O} 21-\mathrm{H} 21$ & $0.81(2)$ & $1.96(3)$ & $177(2)$ & $2.764(2)$ & $\mathrm{O} 22[-\mathrm{x}+0.5,-\mathrm{y}+1.5,-\mathrm{z}]$ \\
$\mathrm{O} 22-\mathrm{H} 22$ & $0.84(2)$ & $2.03(3)$ & $149(2)$ & $2.788(2)$ & $\mathrm{O} 21[\mathrm{x}+0.5, \mathrm{y}-0.5, \mathrm{z}]$ \\
\hline
\end{tabular}




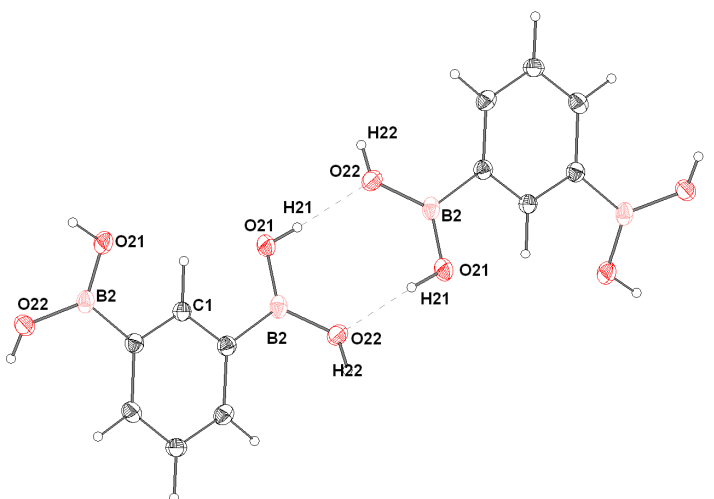

1,3-Phenylenediboronic acid dimer.

Displacement ellipsoids drawn at $50 \%$ probability level.

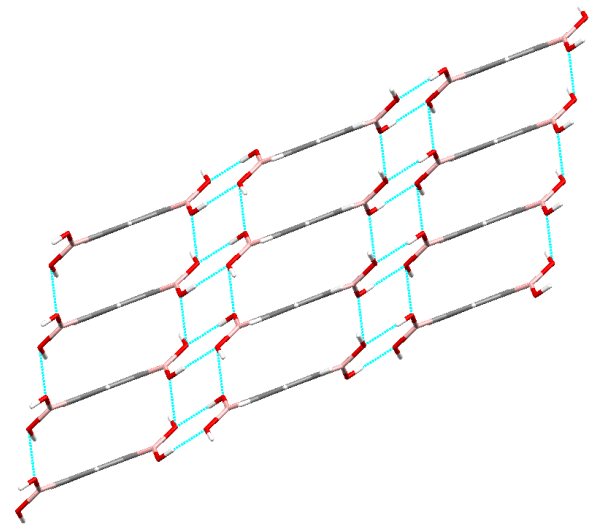

Molecular

interactions

in

1,3-phenylenediboronic acid (view along [010] direction).

(a)

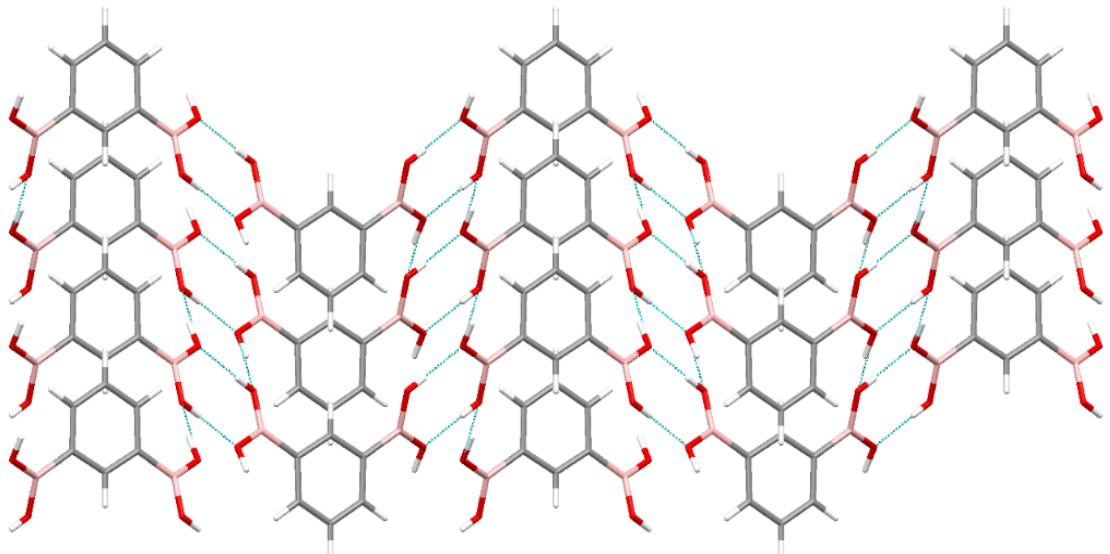

(b)

Figure 6. Infinite ribbon motif (a) and crystal packing of 1,3-phenylenediboronic acid (b).

\subsection{X-ray Powder Diffraction (XRPD)}

The XRPD measurement was performed to study the homogeneity of the on-shelf (commercial) sample of 1,3-phenylenediboronic acid. Diboronic acids tend to crystallize in many different polymorphic and/or solvatomorphic forms, while the crystallization process is strongly influenced by the conditions [13]. Furthermore, boronic and, especially, diboronic/multiboronic acids can dehydrate to corresponding boroxines. As a result, different crystal phases may occur in the sample. The results of XRPD measurements for commercial 1,3-phenylenediboronic acid are shown in Figure 7, together with the theoretical pattern generated from the single-crystal X-ray structure. Both patterns are very similar, confirming the presence of only one phase, which is structurally consistent with that obtained from single-crystal diffraction experiments. 


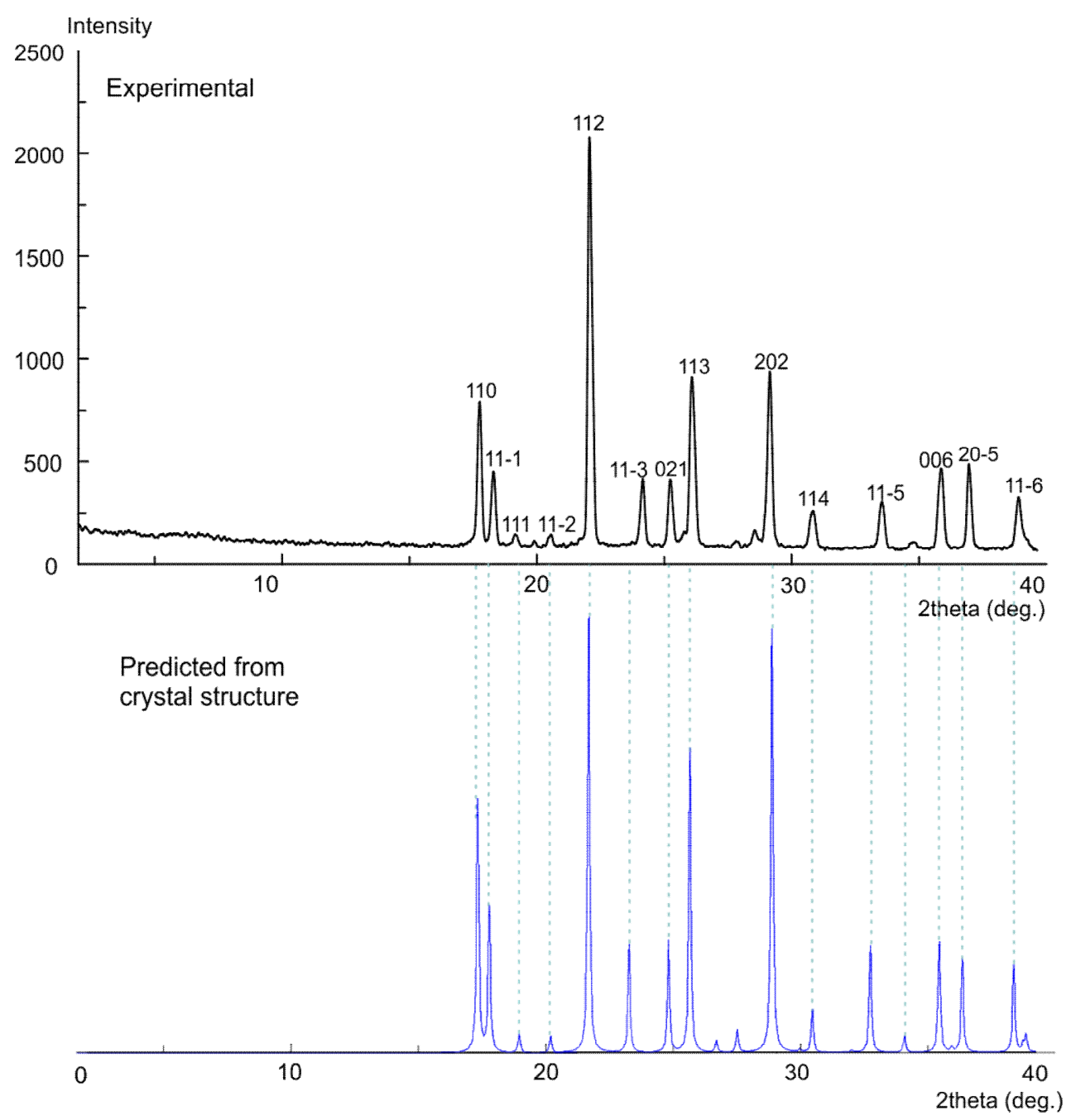

Figure 7. PXRD patterns obtained for studied compound compared to the theoretical pattern generated from the single-crystal $\mathrm{X}$-ray structure.

\subsection{Periodic DFT Calculations}

The calculations in CRYSTAL09 $[27,28]$ have been carried out to compare the total cohesive energy of the title molecule with its previously characterized isomer, namely, $p$-phenylenediboronic acid. The Gaussian calculations were performed in order to estimate the intermolecular interaction energy and, in particular, crystal motifs. The periodic DFT calculations carried out in CRYSTAL09 program at B3LYP/TZVP [30] level of theory show that the cohesive energy of the studied system (after structure optimisation) is equal to $-169.5 \mathrm{~kJ} \cdot \mathrm{mol}^{-1}$. It is, thus, similar to the values found for the structures of $p$-phenylenediboronic acids [8]. Two types of hydrogen-bonded dimers can be distinguished in the structure. These are centrosymmetric dimers leading to the formation of hydrogen-bonded ribbons (Figure 6) (D1) and also dimers formed by the side hydrogen-bond interactions between boronic groups (D2) that connect neighboring chains (Figure 8). The Gaussian calculations on M06-2X/6-311+G(d,p) [34,35] level of theory revealed that the interaction energies are of $-46.2 \mathrm{~kJ} \cdot \mathrm{mol}^{-1}$ and $-38.3 \mathrm{~kJ} \cdot \mathrm{mol}^{-1}$ for D1 and D2 dimers, respectively, (geometries taken from the CRYSTAL09 optimized structures). The topological analysis of electron density distribution reveals that $\mathrm{BCP}$ (Bond Critical Point) of $\mathrm{O}-\mathrm{H} \ldots$. O hydrogen bonds are characterized by relatively high values of electron density, $\rho\left(r_{\mathrm{BCP}}\right)$, of $0.257 \mathrm{e} \cdot \AA^{-3}$ (D1, both hydrogen bonds) and $0.191 \mathrm{e} \cdot \AA^{-3}$ (D2). The Laplacian of electron density, $\nabla^{2} \rho\left(r_{\mathrm{BCP}}\right)$, is positive and equals to $3.40 \mathrm{e} \cdot \AA^{-5}$ (D1) and 2.86 $\mathrm{e} \cdot \AA^{-5}$ (D2) respectively, indicating strong character of those bonds. In addition to hydrogen-bond 
interactions, the structure is supported by dimeric B ... O interactions formed within D3 type dimers, and also $\mathrm{C}-\mathrm{H} \ldots \mathrm{O}$ contacts defining D4 dimers (Figure 9). The calculated interaction energies for those dimers are $-9.0 \mathrm{~kJ} \cdot \mathrm{mol}^{-1}$ and $-2.9 \mathrm{~kJ} \cdot \mathrm{mol}^{-1}$, respectively. The AIM analysis shows the formation of several bond paths between two boronic groups (Figure 9) and also bond paths of $\mathrm{C}-\mathrm{H}$ $\ldots$ O interaction with a relatively small value of $\rho\left(r_{\mathrm{BCP}}\right)$ at $\mathrm{BCP}$ of $0.014 \mathrm{e} \cdot \AA^{-3}$ and $\nabla^{2} \rho\left(r_{\mathrm{BCP}}\right)$ equal to $0.20 \mathrm{e} \cdot \AA^{-5}$.
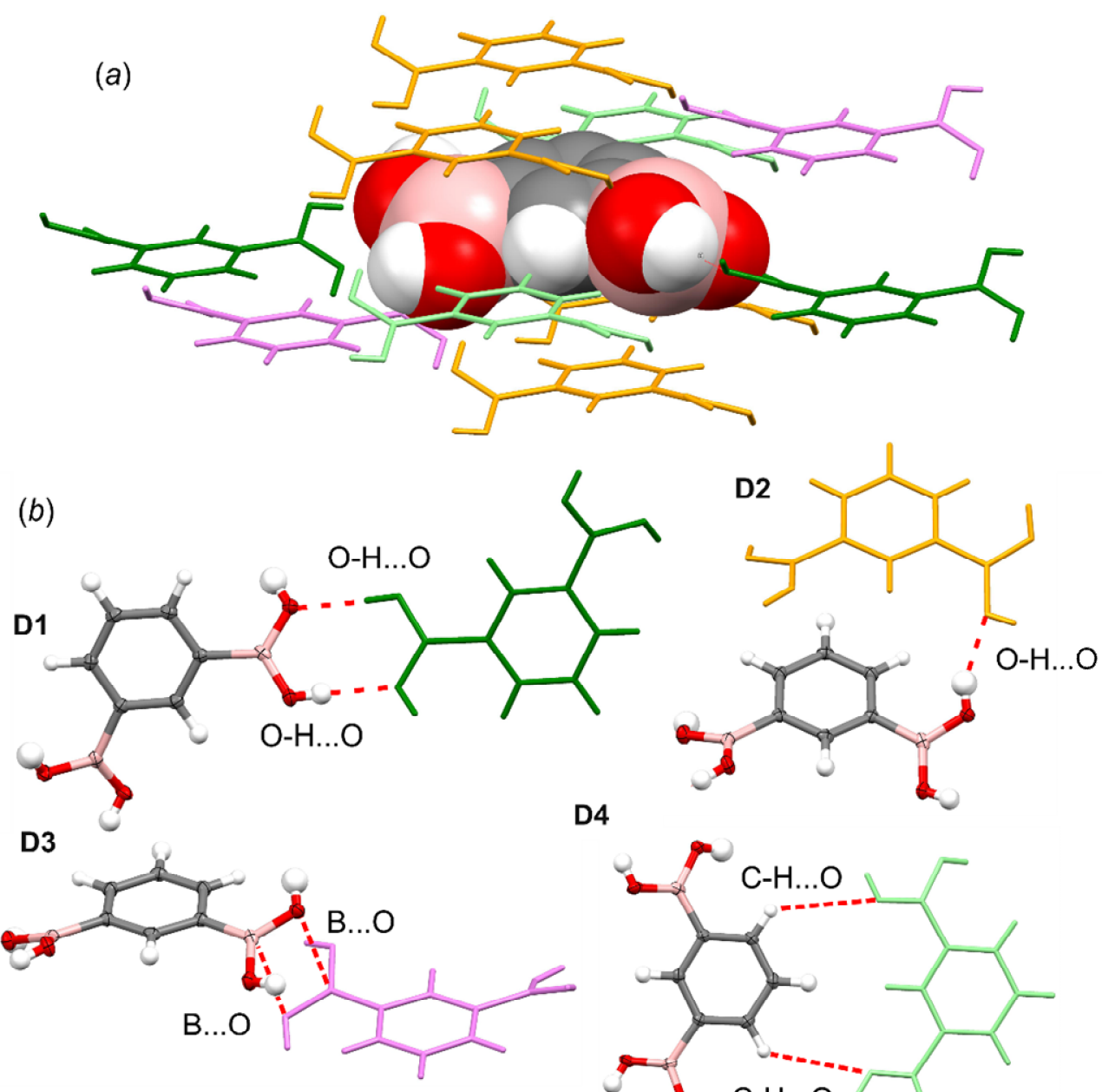

(c)

D4
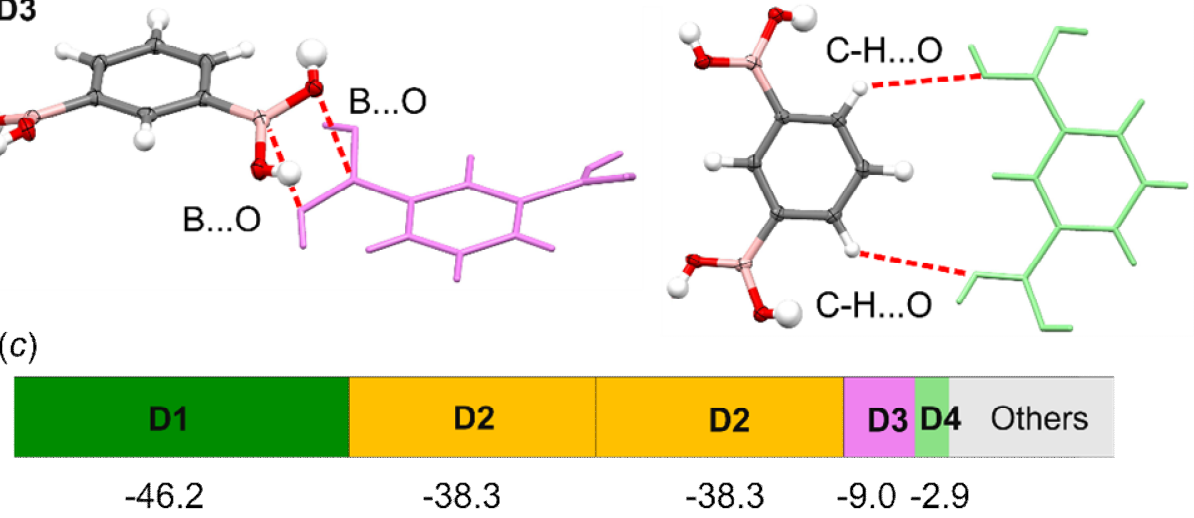

Figure 8. (a) Closest molecular environment (b) with the dispositions of dimeric motifs and (c) contribution of dimers to total cohesive energy in the crystalline state of $m$-phenylenediboronic acid. 

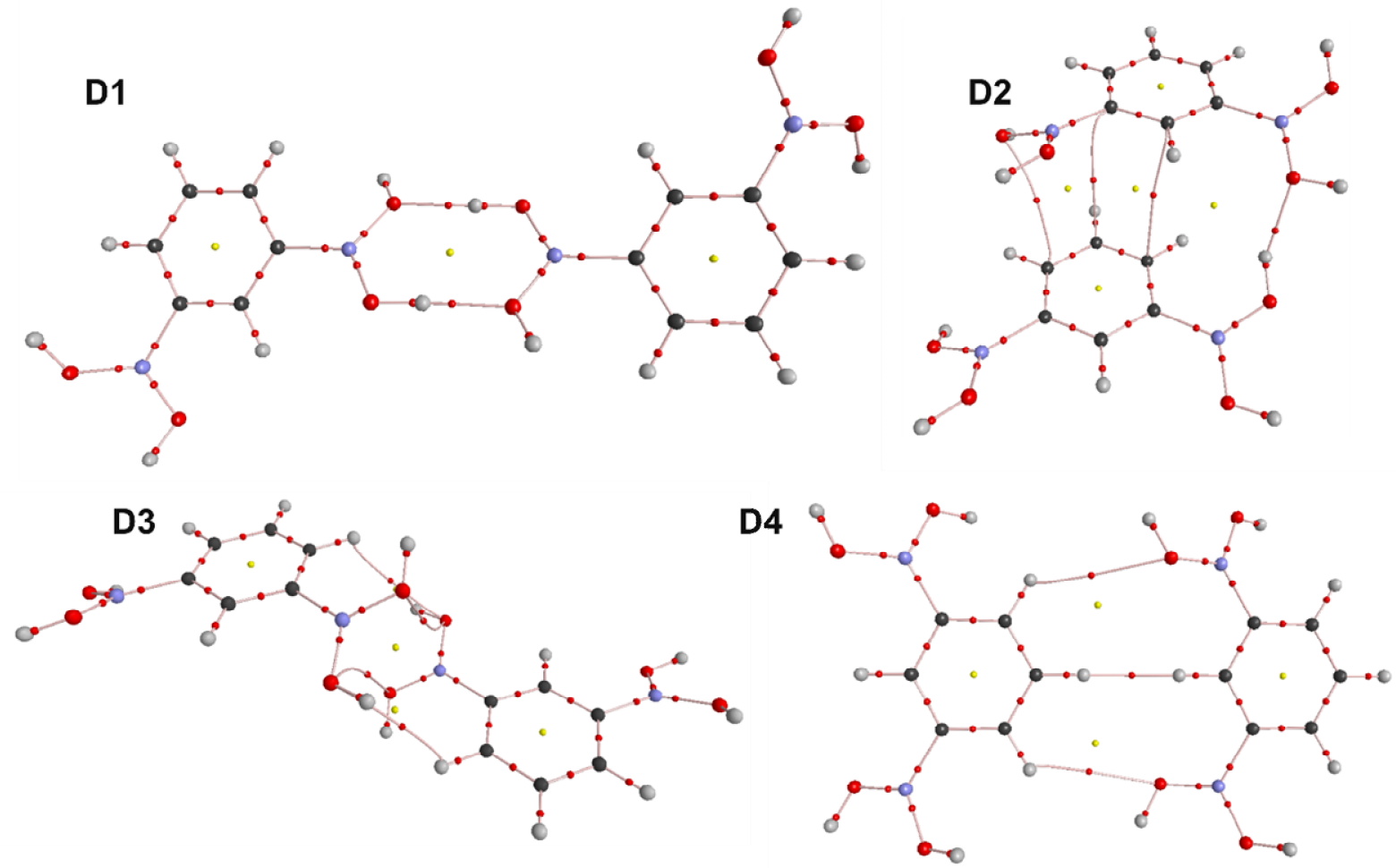

Figure 9. Molecular graph showing the formation $\mathrm{O}-\mathrm{H} \ldots \mathrm{O}$ and $\mathrm{C}-\mathrm{H} \ldots$. O interactions within dimeric motifs D1-D4 together with the disposition of critical points of electron density (Bond Critical Point $(3,-1)$ —red, Ring Critical Point $(3,+1)$-bright yellow).

\subsection{Rotation Barrier}

It has been already pointed out that the rotation barrier for the twist of the boronic group with respect to the phenyl ring fragment is relatively small. It was estimated as $17.5 \mathrm{~kJ} \cdot \mathrm{mol}^{-1}$ for phenylboronic acid (M06-2X/6-311+G(d,p) indicating the planar conformation as the most stable one (Figure 10) [41]. Although the boronic group does not conjugate effectively with the ring [43,44] and the meta position does not favor conjugation through the ring, the analysis of the rotation energy profile for distortion of both boronic groups from planarity leads to interesting findings. The energy hypersurface, shown in Figure 11, reveals that the barrier is $37.1 \mathrm{~kJ} \cdot \mathrm{mol}^{-1}$ (going from planar to perpendicular conformations). This is somewhat higher than a doubled value accounted for by a single group at this level of theory $\left(2 \times 17.5 \mathrm{~kJ} \cdot \mathrm{mol}^{-1}\right)$, indicating a subtle synergic effect. Indeed, the intramolecular contacts between hydroxyl group and $\mathrm{C}-\mathrm{H}$ hydrogen atom influence the relative molecular stabilization energy. Specifically, weak intramolecular C-H ... O interaction between oxygen atom from syn-conformed hydroxyl group makes the planar conformation more stable, which results in a rise of the rotation barrier. This effect is partially counterbalanced by repulsion between hydrogen atoms from a anti-conformed hydroxyl group and aromatic ring $(\mathrm{O}-\mathrm{H}$ ... H-C). In $m$-phenylenediboronic acid, three possible planar conformers (depicted on Figure 11) interact in slightly different ways with the $\mathrm{C}-\mathrm{H}$ hydrogen atom located in-between boronic groups. The most stable is the conformation with only one $\mathrm{C}-\mathrm{H} \ldots$. O hydrogen bond formed with a central $\mathrm{C}-\mathrm{H}$ hydrogen atom. As a result of $\mathrm{O}$ and $\mathrm{H}$ attraction, the $\mathrm{C}-\mathrm{C}-\mathrm{H}$ bond angle decreases $\left(116^{\circ}\right)$, which is a similar behavior observed in the structure of phenylboronic acid, where such angle equals $117^{\circ}$. On the other hand, the $\mathrm{C}-\mathrm{H} \ldots \mathrm{O}$ interaction partially releases the $\mathrm{O}-\mathrm{H} \ldots \mathrm{H}-\mathrm{C}$ hindrance with an anti-conformed hydroxyl group from second boronic group (the $\mathrm{C}-\mathrm{C}-\mathrm{H}$ bond angle is $123^{\circ}$ ). Interestingly, it seems that the formation of a second $\mathrm{C}-\mathrm{H}$... O hydrogen bond with the same hydrogen atom is energetically less favored. This is due to the saturation of the $\mathrm{C}-\mathrm{H}$ hydrogen atom, while the outer anti-conformed hydroxyl groups are engaged in unfavored $\mathrm{O}-\mathrm{H} \ldots \mathrm{H}-\mathrm{C}$ contacts (Figure 11). 
Thus, this conformation is less stable by $4.9 \mathrm{~kJ} \cdot \mathrm{mol}^{-1}$ with respect to the most stable one. On the other hand, it is resembled in the crystal lattice, indicating a strong effect of intermolecular interactions.

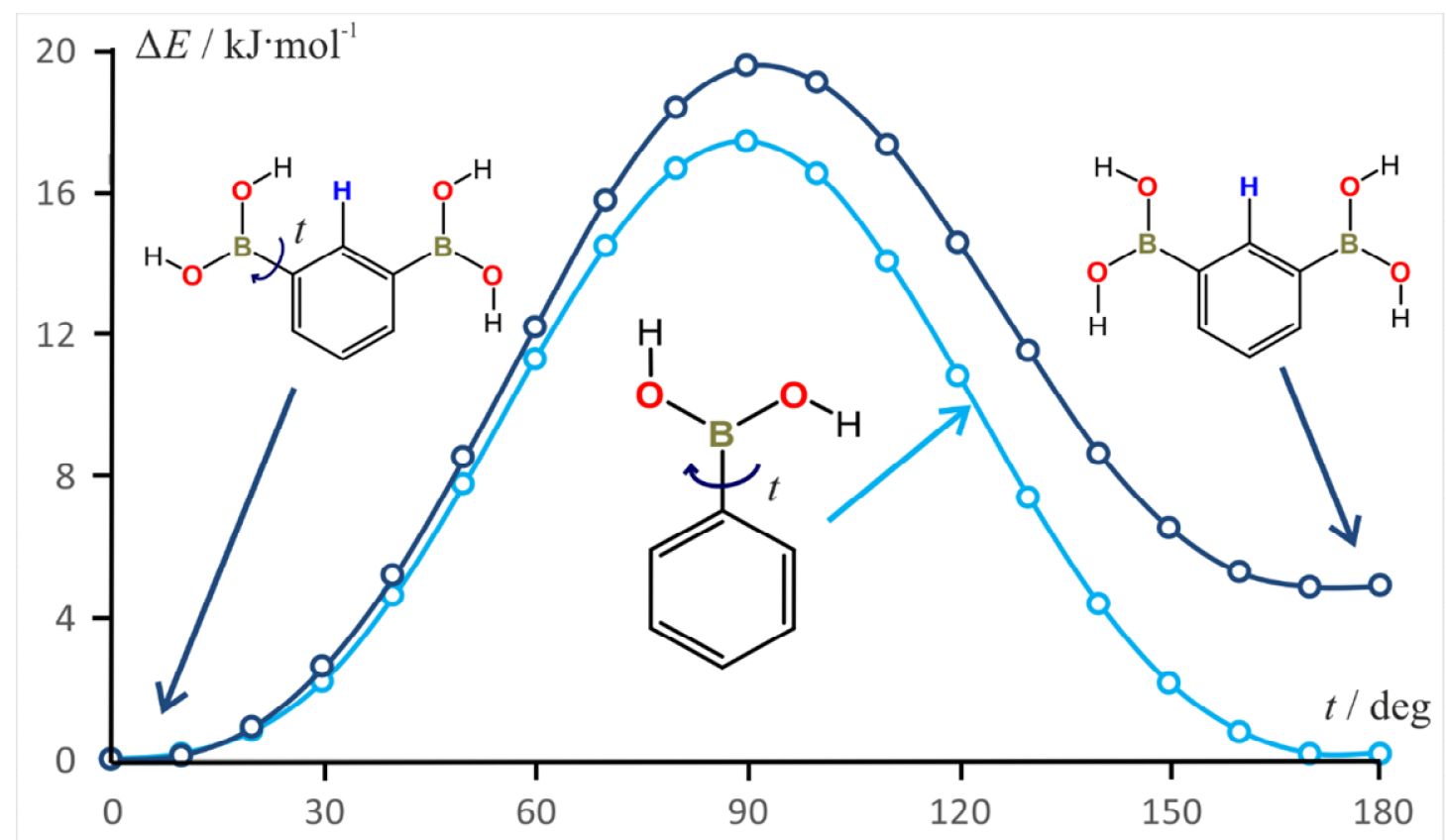

Figure 10. The energy profile for rotation of one boronic groups in respect to the phenylene ring fragment in phenylboronic acid (light blue) and $m$-phenylenediboronic acid (navy blue). The dihedral angle of the second boronic group is fixed to $0^{\circ}$.
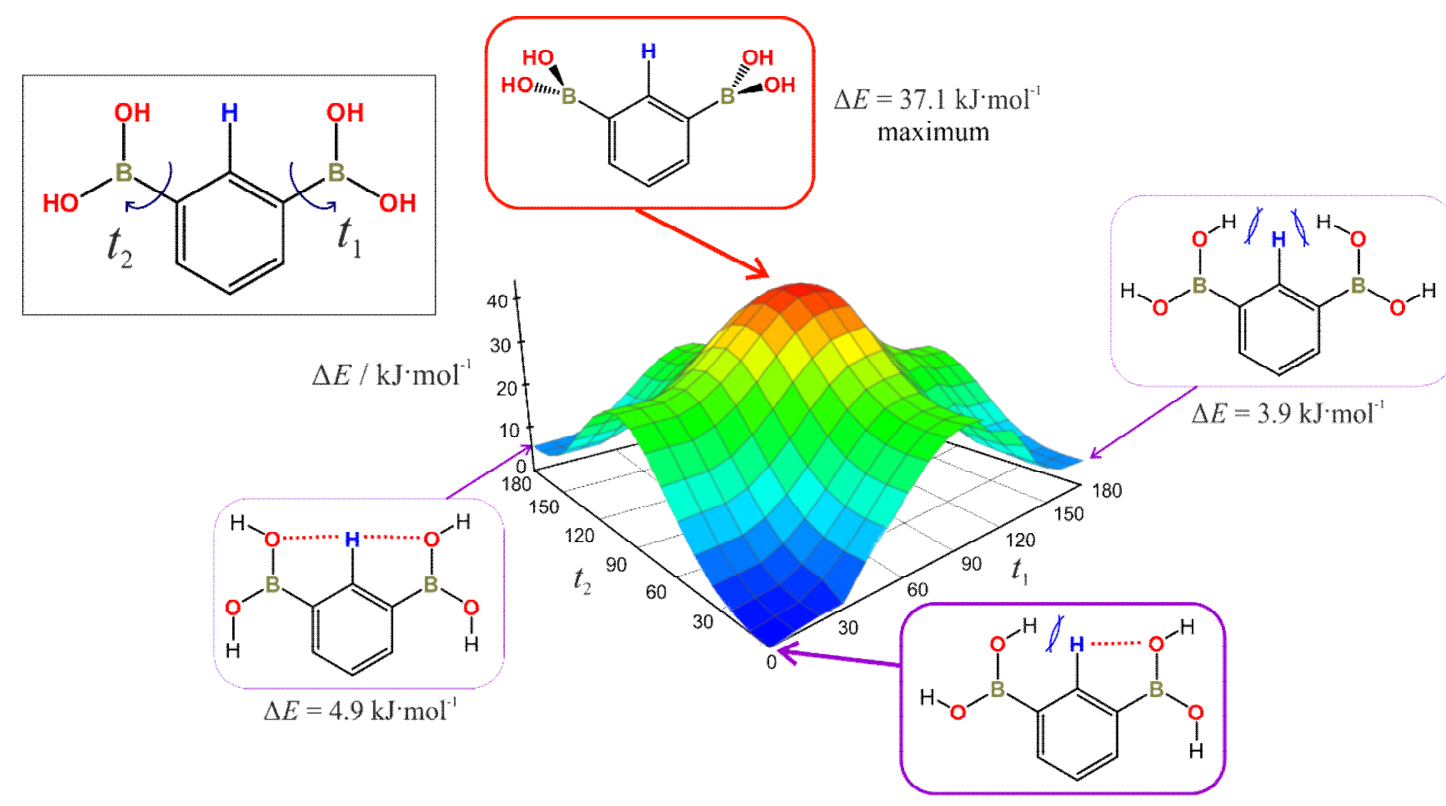

$\Delta E=0.0 \mathrm{~kJ} \cdot \mathrm{mol}$ global minimum

Figure 11. The energy profile for rotation of two boronic groups in respect to the phenylene ring fragment.

\section{Conclusions}

1,3-Phenylenediboronic acid was characterized both in solution and in solid state. The acid-base equilibrium is described by a two-step reaction, which corresponds to two $\mathrm{p} K_{\mathrm{a}}$ values. The results 
obtained by two methods show good agreement. NMR spectra are typical, and signal assignment was made on the basis of ${ }^{1} \mathrm{H}^{-13} \mathrm{C}$ HSQC spectrum. The DSC and thermal analyses curves show a typical dehydration reaction with the formation of boroxines, which probably have an amorphous polymeric structure. On the basis of the single crystal XRD experiment, it was found that the title compound molecules form centrosymmetric dimers with the most common syn-anti conformation of hydroxyl groups. In the crystal lattice, large numbers of ribbon motifs are formed by lateral hydrogen bonds. The XRPD experimental curve shows very good agreement with a theoretical pattern predicted from the crystal structure.

Theoretical calculations show that the rotation barrier for the two boronic groups is slightly higher $\left(37.1 \mathrm{~kJ} \cdot \mathrm{mol}^{-1}\right)$ than the double value accounting for the rotation of a boronic group in phenylboronic acid $\left(17.5 \mathrm{~kJ} \cdot \mathrm{mol}^{-1}\right)$. This effect can be ascribed to the presence of a $\mathrm{C}-\mathrm{H} \ldots \mathrm{O}$ interaction, which slightly affects the $\mathrm{C}-\mathrm{C}-\mathrm{H}$ bond angle leading to partial release of $\mathrm{O}-\mathrm{H} \ldots \mathrm{H}-\mathrm{C}$ hindrance. Periodic DFT calculations supported by the Gaussian dimer energy estimation revealed that the hydrogen-bonded centrosymmetric dimer is the most favored crystal motive with interaction energy reaching $46.2 \mathrm{~kJ} \cdot \mathrm{mol}^{-1}$. The side hydrogen-bonded interactions between boronic groups supported by other, dispersive in nature, interactions lead to the formation of a very stable 2D molecular layer. According to the performed calculations, these account for about $72 \%$ of cohesive energy.

Supplementary Materials: The following are available online at http:/ /www.mdpi.com/2073-4352/9/2/109/s1: Table S1: Selected geometrical parameters; Figure S1. Analysis of spectroscopic data: absorbance change at 274 $\mathrm{nm}$ versus $\mathrm{pH}$; Figure S2. Spectrophotometric titration in $\mathrm{pH}$ range 5.5-11.5 in water; Figure S3. Potentiometric titration with fitting of calculated data; Figure S4. One-dimensional NMR spectra of the title compound.

Author Contributions: M.K.C, A.A.-W. and A.S. jointly designed the experiments. K.D. performed the theoretical calculations. J.T.G. carried out the NMR research. P.K. collected the single crystal X-ray data and solved the crystal structure. R.R. conducted powder X-ray diffraction experiments. D.Z. determined $\mathrm{p} K_{\mathrm{a}}$ values.

Acknowledgments: M.K.C. acknowledges Interdisciplinary Centre for Mathematical and Computational Modelling of the University of Warsaw for computational facilities. Theoretical calculations have been carried out in Wroclaw Centre for Networking and Supercomputing (http:/ / www.wcss.pl), grant No. 285. Support of Warsaw University of Technology is kindly acknowledged.

Conflicts of Interest: The authors declare no conflict of interest.

\section{References}

1. WILEY-VCH. Boronic Acids. Preparation and Applications in Organic Synthesis, Medicine and Materials, 2nd ed.; Hall, D.G., Ed.; WILEY-VCH: Weinheim, Germany, 2011.

2. Nishiyabu, R.; Kubo, Y.; James, T.D.; Fossey, J.S. Boronic acid building blocks: Tools for self assembly. Chem. Commun. 2011, 47, 1124-1150. [CrossRef] [PubMed]

3. Adamczyk-Woźniak, A.; Borys, K.M.; Sporzyński, A. Recent Developments in the Chemistry and Biological Applications of Benzoxaboroles. Chem. Rev. 2015, 115, 5224-5247. [CrossRef] [PubMed]

4. Dembitsky, V.M.; Al Quntar, A.A.A.; Srebnik, M. Natural and synthetic small boron-containing molecules as potential inhibitors of bacterial and fungal quorum sensing. Chem. Rev. 2011, 111, 209-237. [CrossRef] [PubMed]

5. Feng, X.; Ding, X.; Jiang, D. Covalent organic frameworks. Chem. Soc. Rev. 2012, 41, 6010-6022. [CrossRef]

6. Ding, S.Y.; Wang, W. Covalent organic frameworks (COFs): From design to applications. Chem. Soc. Rev. 2013, 42, 548-568. [CrossRef] [PubMed]

7. Waller, P.J.; Gándara, F.; Yaghi, O.M. Chemistry of Covalent Organic Frameworks. Acc. Chem. Res. 2015, 48, 3053-3063. [CrossRef] [PubMed]

8. Côté, A.P.; Benin, A.I.; Ockwig, N.W.; O’Keeffe, M.; Matzger, A.J.; Yaghi, O.M. Porous, Crystalline, Covalent Organic Frameworks. Science 2005, 310, 1166-1170. [CrossRef]

9. Adamczyk-Woźniak, A.; Sporzyński, A. Diboronic Acids and Their Derivatives: New Perspectives in Sensing and Materials' Chemistry. In Advances in Materials Science Research Vol. 32; Wythers, M.C., Ed.; Nova Science Publishers, Inc.: New York, NY, USA, 2018; pp. 201-233. ISBN 978-1-53613-329-5.

10. Rodríguez-Cuamatzi, P.; Vargas-Díaz, G.; Maris, T.; Wuest, J.D.; Höpfl, H. 1,4-Phenylenediboronic acid. Acta Crystallogr. Sect. E Struct. Rep. Online 2004, E60, o1316-o1318. [CrossRef] 
11. Rodríguez-Cuamatzi, P.; Vargas-Díaz, G.; Höpfl, H. Modification of 2D water that contains hexameric units in chair and boat conformations-A contribution to the structural elucidation of bulk water. Angew. Chem. Int. Ed. 2004, 43, 3041-3044. [CrossRef]

12. Maly, K.E.; Maris, T.; Wuest, J.D. Two-dimensional hydrogen-bonded networks in crystals of diboronic acids. CrystEngComm 2006, 8, 33-35. [CrossRef]

13. Durka, K.; Jarzembska, K.N.; Kamiński, R.; Luliński, S.; Serwatowski, J.; Woźniak, K. Nanotubular hydrogen-bonded organic framework architecture of 1,2-phenylenediboronic acid hosting ice clusters. Cryst. Growth Des. 2013, 13, 4181-4185. [CrossRef]

14. Durka, K.; Luliński, S.; Serwatowski, J.; Woźniak, K. Influence of fluorination and boronic group synergy on the acidity and structural behavior of o-phenylenediboronic acids. Organometallics 2014, 33, 1608-1616. [CrossRef]

15. Jarzembska, K.N.; Kaminski, R.; Durka, K.; Kubsik, M. Engineering of solvatomorphs of the luminescent complex of ortho-phenylenediboronic acid and 8-hydroxyquinoline. Cryst. Growth Des. 2017, 17, 6836-6851. [CrossRef]

16. Dabrowski, M.; Luliński, S.; Serwatowski, J. (2-Methoxy-1,3-phenylene)diboronic acid.aActa Crystallogr. Sect. E Struct. Rep. Online 2008, 64, o414-o415. [CrossRef] [PubMed]

17. Durka, K.; Luliński, S.; Smętek, J.; Dabrowski, M.; Serwatowski, J.; Woźniak, K. The influence of boronate groups on the selectivity of the Br-Li exchange in model dibromoaryl boronates. Eur. J. Org. Chem. 2013, 2013, 3023-3032. [CrossRef]

18. Rodríguez-Cuamatzi, P.; Luna-García, R.; Torres-Huerta, A.; Bernal-Uruchurtu, M.I.; Barba, V.; Höpfl, H. On the Organizing Role of Water Molecules in the Assembly of Motifs \& DESIGN 2009. Cryst. Growth Des. 2009, 9, 1575-1583.

19. Kostrowicki, J.; Liwo, A. Determination of equilibrium parameters by minimization of an extended sum of squares. Talanta 1990, 37, 645-650. [CrossRef]

20. Kostrowicki, J.; Liwo, A. DECFAM-A new computer oriented algorithm for the determination of equilibrium constants from potentionmetric and/or spectrophotometric measurements-I: Basic principles of the method and calculations of equilibrium concentrations. Comput. Chem. 1984, 8, 91-99. [CrossRef]

21. Kostrowicki, J.; Liwo, A. DECFAM-A new computer oriented algorithm for the determination of equilibrium constants from potentiometric and/or spectrophotometric measurements-II: Methods based on analytical expressions. Comput. Chem. 1984, 8, 101-105. [CrossRef]

22. Chylewska, A.; Jacewicz, D.; Zarzeczańska, D.; Chmurzyński, L. Determination of dissociation constants for coordination compounds of $\mathrm{Cr}(\mathrm{III})$ and $\mathrm{Co}(\mathrm{III})$ using potentiometric and spectrophotometric methods. J. Chem. Thermodyn. 2008, 40, 1290-1294. [CrossRef]

23. Oxford Diffraction Ltd. CrysAlis CCD and CrysAlis RED 2001, version 1.171.28 cycle2 beta; Oxford Diffraction Ltd.: Wrocław, Poland, 2005.

24. Sheldrick, G.M. Phase annealing in SHELX-90: Direct methods for larger structures. Acta Crystallogr. Sect. A Found. Adv. 1990, 46, 467-473. [CrossRef]

25. Sheldrick, G.M. SHELXL93. Program for the Refinement of Crystal Structures; University of Göttingen: Göttingen, Germany, 1993.

26. International Union of Crystallography. International Tables for Crystallography: Mathematical, Physical, and Chemical Tables; Wilson, A.J.C., Ed.; International Union of Crystallography: Chester, UK, 1992; Volume 3.

27. Dovesi, R.; Orlando, R.; Civalleri, B.; Roetti, R.; Saunders, V.R.; Zicovich-Wilson, C.M. CRYSTAL: A computational tool for the ab initio study of the electronic properties of crystals. Zeitschrift für Kristallographie 2005, 220, 571-573. [CrossRef]

28. Dovesi, R.; Saunders, V.R.; Roetti, R.; Orlando, R.; Zicovich-Wilson, C.M.; Pascale, F.; Civalleri, B.; Doll, K.; Harrison, N.M.; Bush, I.J.; et al. CRYSTAL09; University of Torino: Torino, Italy, 2009.

29. Allen, F.H.; Bruno, I.J. Bond lengths in organic and metal-organic compounds revisited: $\mathrm{X}-\mathrm{H}$ bond lengths from neutron diffraction data. Acta Crystallogr. Sect. B Struct. Sci. 2010, 66, 380-386. [CrossRef] [PubMed]

30. Peintinger, M.F.; Oliveira, D.V.; Bredow, T. Consistent Gaussian basis sets of triple-zeta valence with polarization quality for solid-state calculations. J. Comput. Chem. 2013, 34, 451-459. [CrossRef] [PubMed]

31. Grimme, S. Accurate description of van der Waals complexes by density functional theory including empirical corrections. J. Comput. Chem. 2004, 25, 1463-1473. [CrossRef] [PubMed] 
32. Grimme, S. Semiempirical GGA-type density functional constructed with a long-range dispersion correction. J. Comput. Chem. 2006, 27, 1787-1799. [CrossRef] [PubMed]

33. Frisch, M.J.; Trucks, G.W.; Schlegel, H.B.; Scuseria, G.E.; Robb, M.A.; Cheeseman, J.R.; Montgomery, J.A., Jr.; Vreven, T.; Kudin, K.N.; Burant, J.C.; et al. Gaussian09, Revision B.01; Gaussian Inc.: Wallingford, CT, USA, 2010.

34. Zhao, Y.; Truhlar, D.G. The M06 suite of density functionals for main group thermochemistry, thermochemical kinetics, noncovalent interactions, excited states, and transition elements: Two new functionals and systematic testing of four M06-class functionals and 12 other function. Theor. Chem. Acc. 2008, 120, 215-241. [CrossRef]

35. Lee, C.; Yang, W.; Parr, R.G. Development of the Colle-Salvetti correlation-energy formula into a functional of the electron density. Phys. Rev. B 1988, 37, 785-789. [CrossRef]

36. Bader, R.F.W. Atoms in Molecules. A Quantum Theory; Clarendon Press: Oxford, UK, 1990.

37. Popelier, P.L.A.; Aicken, F.M.; O’Brien, S.E. Atoms in Molecules. In Chemical Modelling: Applications and Theory, Vol. 1; Hinchliffe, A., Ed.; Royal Society of Chemistry: Cambridge, UK, 2000; pp. 143-198. ISBN 0-85404-254-7.

38. Biegler-König, F.; Schönbohm, J.; Bayles, D. Software News and Updates. AIM2000—A Program to Analyse and Visualize Atoms in Molecules. J. Comput. Chem. 2001, 22, 545-559. [CrossRef]

39. Zarzeczańska, D.; Adamczyk-Woźniak, A.; Kulpa, A.; Ossowski, T.; Sporzyński, A. Fluorinated Boronic Acids: Acidity and Hydrolytic Stability of Fluorinated Phenylboronic Acids. Eur. J. Inorg. Chem. 2017, 2017, 4493-4498. [CrossRef]

40. Adamczyk-Woźniak, A.; Kaczorowska, E.; Kredátusova, J.; Madura, I.; Marek, P.H.; Matuszewska, A.; Sporzyński, A.; Uchman, M. Dehydration of ortho-, meta- and para-Alkoxy Phenylboronic Acids to their Corresponding Boroxines. Eur. J. Inorg. Chem. 2018, 2018, 1492-1498. [CrossRef]

41. Durka, K.; Jarzembska, K.N.; Kamiński, R.; Luliński, S.; Serwatowski, J.; Woźniak, K. Structural and energetic landscape of fluorinated 1,4-phenylenediboronic acids. Cryst. Growth Des. 2012, 12, 3720-3734. [CrossRef]

42. Filthaus, M.; Oppel, I.M.; Bettinger, H.F. Supramolecular structures and spontaneous resolution: The case of ortho-substituted phenylboronic acids. Org. Biomol. Chem. 2008, 6, 1201-1207. [CrossRef] [PubMed]

43. Jaffe, H.H. A Reexamination of the Hammett Equation. Chem. Rev. 1953, 53, 191-261. [CrossRef]

44. Hansch, C.; Leo, A.; Taft, R.W. A survey of Hammett substituent constants and resonance and field parameters. Chem. Rev. 1991, 91, 165-195. [CrossRef] 